\title{
Study of Mechanisms of Aerosol Indirect Effects on Glaciated Clouds: Progress during the Project
}

\author{
Final Technical Report \\ Period covered: 15 January 2012 - 14 July 2013 \\ (final Year 3 of project, with extra $4^{\text {th }}$ year of no-cost extension) \\ Funding Office: US Department of Energy, Office of Science (BER/ASR program)
}

18 October 2013

Principal Investigator (PI): Vaughan Phillips

The PI is now at University of Lund, Department of Physical Geography and Ecosystem Science, Solvegatan 12, Lund, Sweden.

Performing organization: School of Earth and Environment, University of Leeds, Leeds, United Kingdom. 
Final Technical Report

\title{
Study of Mechanisms of Aerosol Indirect Effects on Glaciated Clouds:
}

\section{Progress during the Project}

Principal Investigator (PI): Vaughan Phillips

\begin{abstract}
This 3-year project has studied how aerosol pollution influences glaciated clouds. The tool applied has been an 'aerosol-cloud model'. It is a type of Cloud-System Resolving Model (CSRM) modified to include 2-moment bulk microphysics and 7 aerosol species, as described by Phillips et al. $(2009,2013)$. The study has been done by, first, improving the model and then performing sensitivity studies with validated simulations of a couple of observed cases from ARM. These are namely the Tropical Warm Pool International Cloud Experiment (TWP-ICE) over the tropical west Pacific and the Cloud and Land Surface Interaction Campaign (CLASIC) over Oklahoma.

During the project, sensitivity tests with the model showed that in continental clouds, extra liquid aerosols (soluble aerosol material) from pollution inhibited warm rain processes for precipitation production. This promoted homogeneous freezing of cloud droplets and aerosols. Mass and number concentrations of cloud-ice particles were boosted. The mean sizes of cloud-ice particles were reduced by the pollution. Hence, the lifetime of glaciated clouds, especially ice-only clouds, was augmented due to inhibition of sedimentation and ice-ice aggregation. Latent heat released from extra homogeneous freezing invigorated convective updrafts, and raised their maximum cloud-tops, when aerosol pollution was included.

In the particular cases simulated in the project, the aerosol indirect effect of glaciated clouds was twice than of (warm) water clouds. This was because glaciated clouds are higher in the troposphere than water clouds and have the first interaction with incoming solar radiation. Ice-only clouds caused solar cooling by becoming more extensive as a result of aerosol pollution. This 'lifetime indirect effect' of iceonly clouds was due to higher numbers of homogeneously nucleated ice crystals causing a reduction in their mean size, slowing the ice-crystal process of snow production and slowing sedimentation. In addition to the known indirect effects (glaciation, riming and thermodynamic), new indirect effects were discovered and quantified due to responses of sedimentation, aggregation and coalescence in glaciated clouds to changing aerosol conditions. In summary, the change in horizontal extent of the glaciated clouds ('lifetime indirect effects'), especially of ice-only clouds, was seen to be of higher importance in regulating aerosol indirect effects than changes in cloud properties ('cloud albedo indirect effects').
\end{abstract}




\section{Table of Contents}

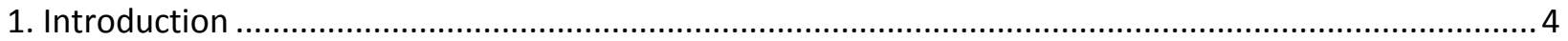

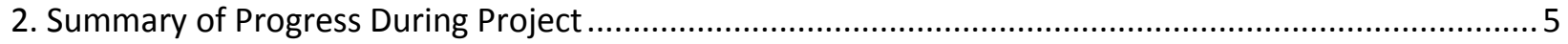

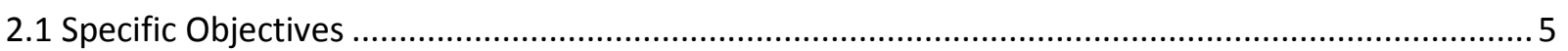

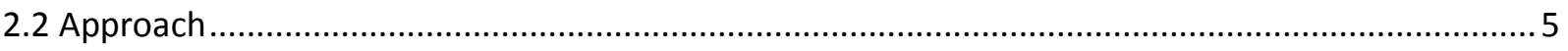

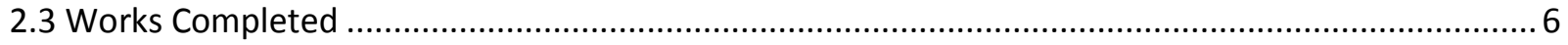

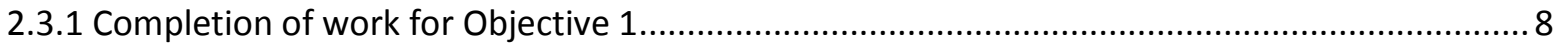

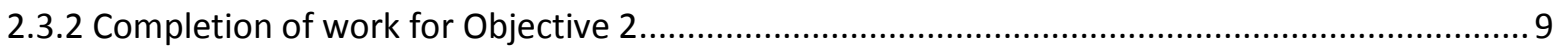

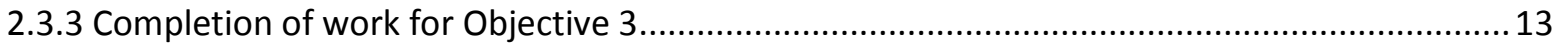

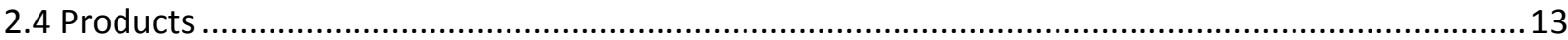

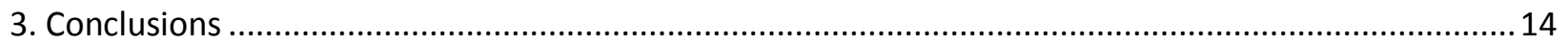

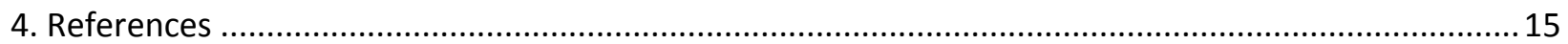




\title{
Final Technical Report
}

\section{Study of Mechanisms of Aerosol Indirect Effects on Glaciated Clouds - Progress during the Project}

\author{
Report period: 15 January 2012 - 14 July 2013 (Year 3 of project, with extra year of no-cost extension) \\ Project duration: August 2009 - July 2013 \\ Principal Investigator (PI): Vaughan Phillips
}

\section{Introduction}

Since 1800, manufacturing output has increased worldwide and led to greater loadings of aerosol particles in the troposphere relative to pre-industrial times. Globally, there is still an increasing burden of aerosol from pollution primarily due to countries in Asia, particularly China and India (Streets et al., 2003). Most of the developed countries have already reached their peak in emissions of aerosol particles from pollution. Emissions from biomass-burning continue to increase in the southern hemisphere. Hence, globally the aerosol conditions of chemistry and loading in the troposphere have been artificially altered, especially in terms of sulfate and carbonaceous aerosols.

According to the Intergovernmental Panel on Climate Change (IPCC) (Soloman et al., 2007), increases in anthropogenic aerosols are one of the major forcing agents for climate change. They affect climate radiatively by two major pathways. Firstly, in clear-sky regions of the atmosphere, aerosols can scatter shortwave radiation. Increasing the reflection of sunlight to space, which cools the climate. This is called the aerosol direct effect. The second pathway is when extra anthropogenic aerosol particles act first, as Cloud Condensation Nuclei (CCN) or Ice Nuclei (IN), and initiate cloud particles. Thus, changes in chemical composition and loading of aerosol particles in the troposphere may modify the microphysical and optical properties of clouds, altering the Earth's radiation budget. This second mechanism is referred to as the aerosol indirect effect (Lohmann and Feichter, 2005).

Quantification of indirect effects from aerosol pollution have so far focused on warm clouds. Indirect effects via glaciated clouds were not assessed in the last IPCC report. The complexity of the task of relating ice initiation to aerosol conditions in models, and treating precipitation production in glaciated clouds, is what makes the aerosol/cold-cloud linkage difficult to treat.

Consequently, with the aim of filling this gap in knowledge, the present 3-year project has studied how aerosol pollution influences glaciated clouds. Numerical simulations of mesoscale cloud systems have been performed with an 'aerosol-cloud model' so as to characterize the salient microphysical and dynamical pathways for indirect effects. This model is a type of Cloud-System Resolving Model (CSRM) with 2-moment bulk microphysics and 7 aerosol species, as described by Phillips et al. (2009). It was created by the PI in the software infrastructure of the Weather, Research and Forecasting (WRF) model. As explained by Phillips et al. $(2009,2013)$, our aerosol-cloud model treats all known and fully 
empirically quantified mechanisms of ice initiation, in terms of fundamental dependencies on conditions of aerosol chemistry, size and loading. Thus, the linkage between cold cloud properties and aerosol conditions of chemistry, size and loading is simulated and studied.

\section{Summary of Progress During Project}

\subsection{Specific Objectives}

In Years 1 and 2, the study was accomplished by first improving the model and then performing sensitivity studies with validated simulations of a couple of observed cases from ARM. These are namely the Tropical Warm Pool International Cloud Experiment (TWP-ICE) over the tropical west Pacific and the Cloud and Land Surface Interaction Campaign (CLASIC) over Oklahoma.

For this final Year 3 of the report period, key Objectives (see "Project Description" of original proposal, Sections 4.3, 4.4 therein) were:-

(1) "Validate the simulations of both ARM cases, with aircraft, satellite and ground-based observations, with particular focus given to predicted number concentrations and sizes of cloud-particles, precipitation rates, and radiative fluxes at TOA and surface" (continued from Year 2);

(2) "Perform sensitivity tests to elucidate the role of soluble aerosol on glaciated cloud properties and cloud extent, analysing the change in reflected shortwave and outgoing longwave radiation at TOA;"

(3) "Perform sensitivity tests to show how insoluble aerosol impacts cloud properties and cloud extent;"

(4) "Write and submit papers".

During the report period for the final year of the project, Objectives (1)-(3) were finished. Objective (4) is currently underway, as the PhD student is writing a thesis describing the results. It will be submitted for examination at University of Leeds before the end of 2013.

\subsection{Approach}

During the report period (final Year 3) our general approach for understanding better the mechanisms for how aerosol conditions control cold clouds has been to analyse carefully the production of species of hydrometeor in the control simulations. This has been done with two techniques, using the aerosolcloud model:

- Sensitivity tests using validated simulation; 
- Budgets of numbers of ice crystals and droplets from various types of initiation.

During the report period, such an approach was followed with this sequence of Steps for achieving Objectives 2 and 3 (Sec. 2.1):-

(a) Collaborate with scientists of both field campaigns to initialize the aerosol profiles for all species as realistically as possible, and to obtain the best possible products from aircraft observations for validation;

(b) Analyse the simulated microphysical responses in the sensitivity studies by plotting microphysical profiles of ice and liquid, and performing budgets of number of cloud-particles generated by the various mechanisms of initiation, so as to understand the microphysical mechanisms for the indirect effects from pollution;

(c) Use multiple alternative methods for measuring each type of indirect effect in the simulations, so as to have more confidence in the analysis;

(d) Perform extra sensitivity studies to analyse the microphysical production of cloud-particles and precipitation in the cloud.

Equally, in the previous Year 2, careful validation of the aerosol-cloud model was performed in order to enable model biases to be reduced. This validation continued during Year 3. Such a combination of model improvements and validation continued during the report period, ensuring reliability of the assessment of mechanisms of indirect effects in Steps (a)-(d).

\subsection{Works Completed}

The major tasks performed during the report period involved performing sensitivity tests with the validated cloud model. Steps (a)-(d) (Sec. 2.2) were followed. Now, at the end of the report period, the objectives for the final report period (Sec. 2.1) have mostly been accomplished, as outlined below. Work on writing up the project results will continue during 2013-2014 as the PhD student finishes a PhD dissertation and then submits papers to peer-reviewed journals.

Key model improvements during the project were treatment of size-dependent ice morphology, inclusion of prediction of the mean size of sulphate aerosols (Year 2) and separate treatments of nonbiological and primary-biological insoluble organic aerosol material (Year 3). The model improvements were motivated partly by the PI's findings, which were published during the report period (Khain et al. 2012; Morris et al. 2013), that primary biological aerosols and small soluble aerosols (e.g. sulphate) control rates of ice nucleation and in-cloud droplet activation respectively. The latest version of the empirical parameterization of heterogeneous ice nucleation was described in another paper by Phillips et al. (2013) and implemented in the model, treating initiation of cloud-ice by soluble organic aerosols (Year 3). Also, the PhD student assisted in efforts to improve treatment of 'sticking efficiencies' 

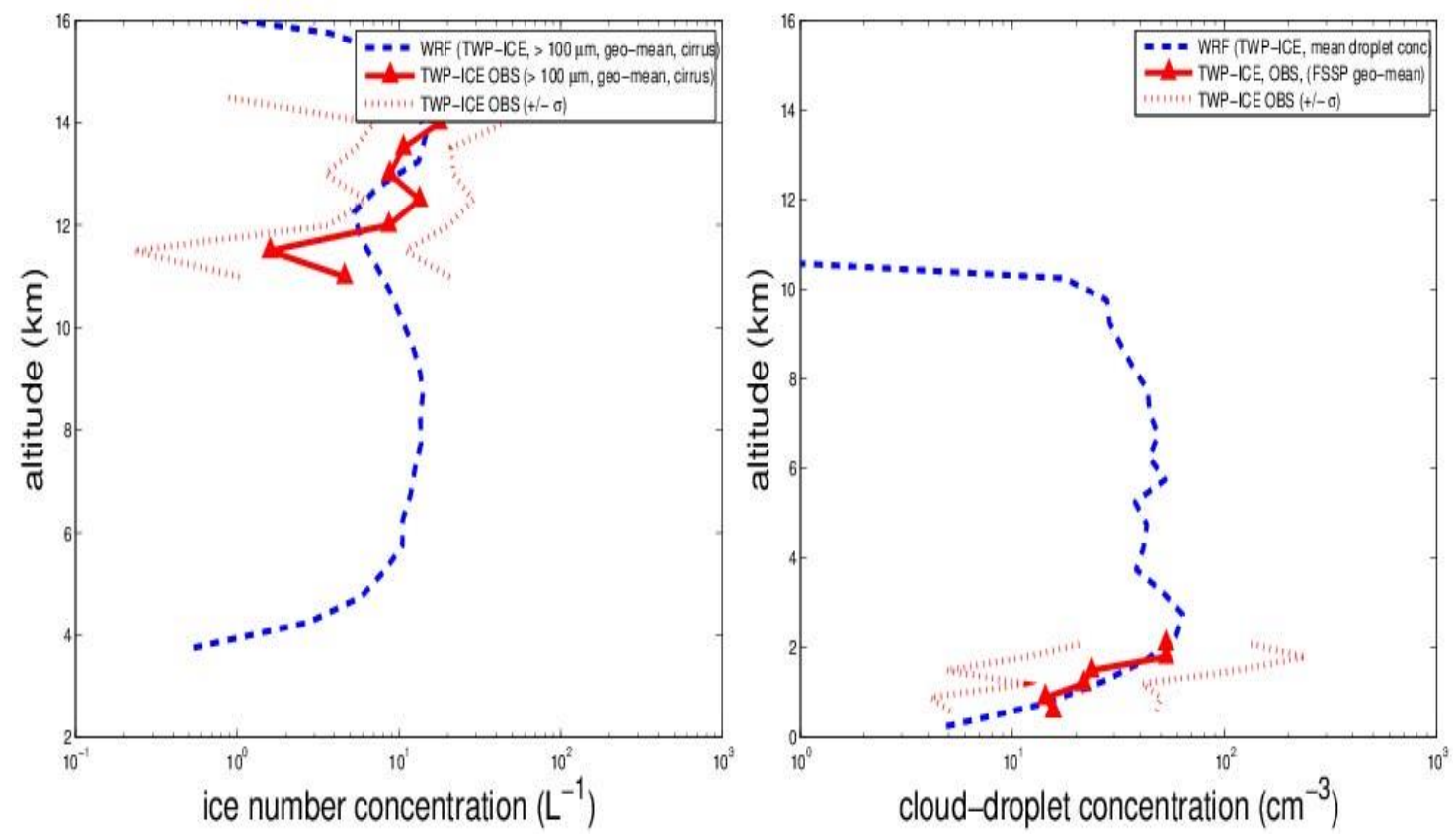

Figure 1: Cloud-particle number concentrations predicted (blue) and compared to aircraft data (red), for the TWP-ICE case of deep convection over Darwin in the tropical West Pacific.
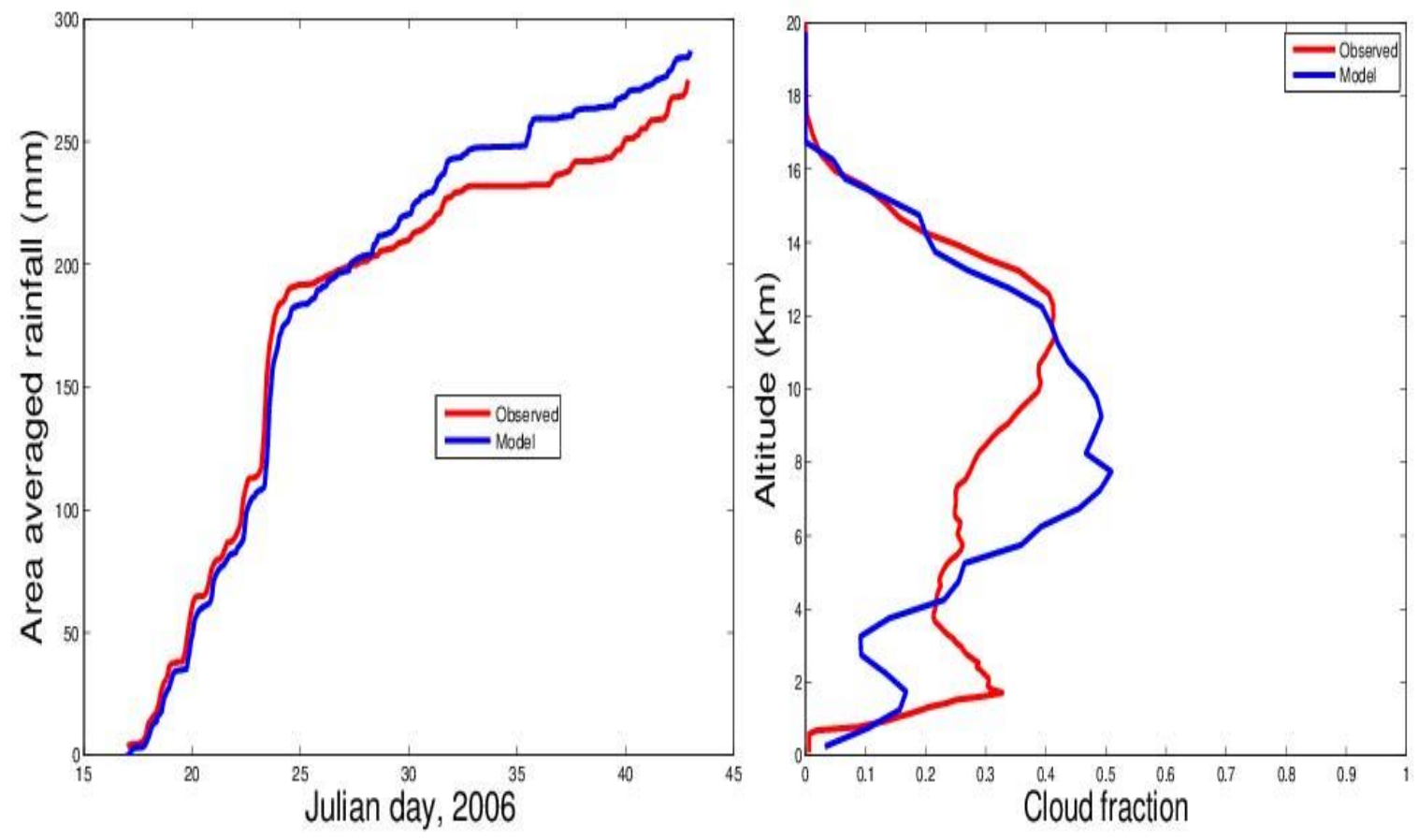

Figure 2: Time evolution of accumulated surface precipitation (left) and the vertical profile of average cloud fraction (right), predicted by the aerosol-cloud model (blue) and observed by ARM (red) during TWP-ICE in the tropical West Pacific. 

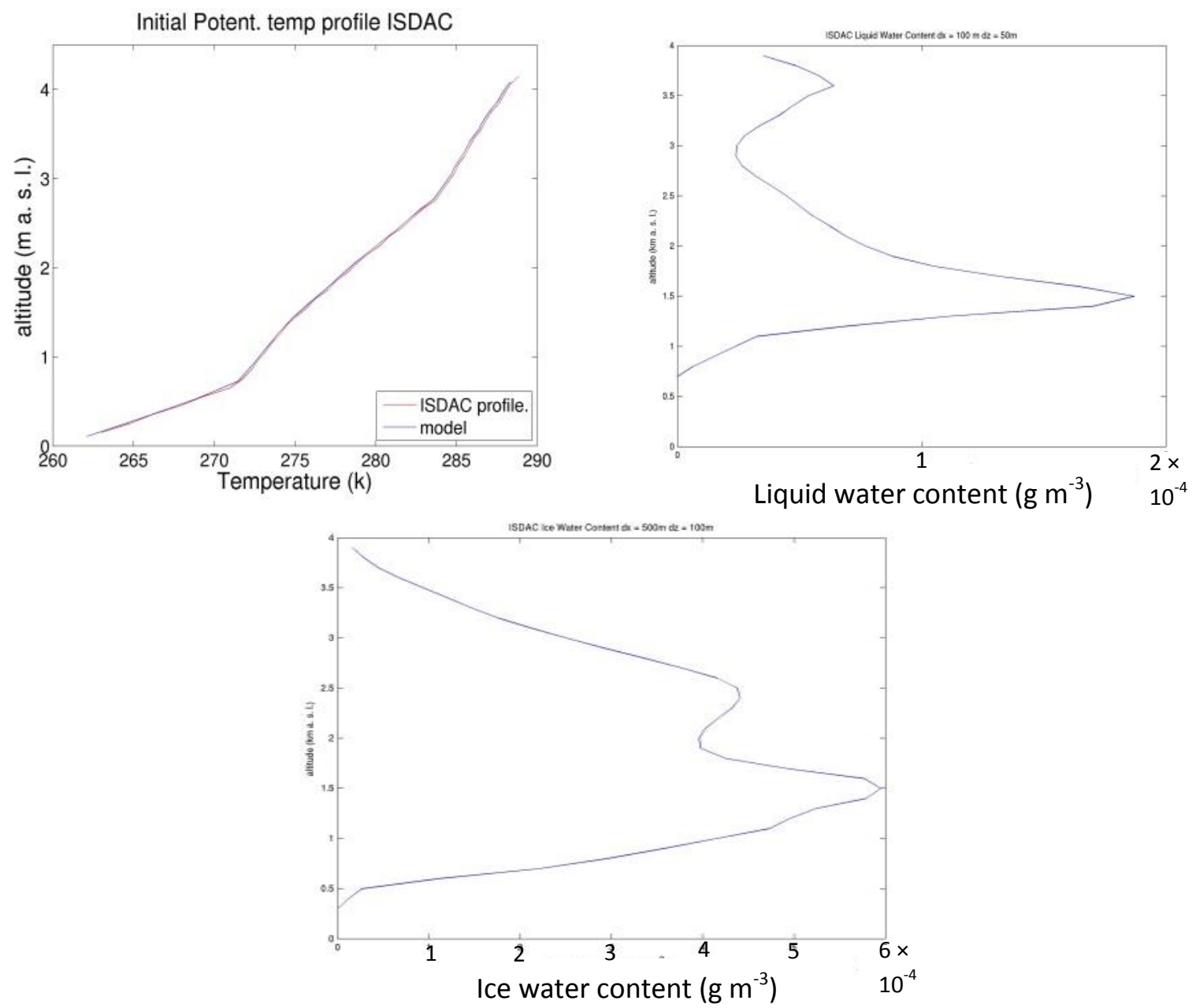

Figure 3: Mixed-phase stratocumulus cloud over the Arctic ocean in the ISDAC case simulated by the aerosolcloud model with a horizontal resolution of about $0.5 \mathrm{~km}$. The initial sounding of potential temperature is stable, typical of the polar boundary layer (upper left). Shown is LWC (upper right) and IWC (lower), averaged over the entire domain for $\mathbf{1 1}$ hours of simulation. Profiles are plotted in terms of altitude above sea level. The model is driven by tendencies of large-scale advection of heat and moisture derived by ISDAC scientists. Lateral boundary conditions are periodic.

(probability of two ice particles sticking together, given that they collide) for ice-ice aggregation (Year 3). In the latest version of the aerosol-cloud model, the sticking efficiencies have been treated more realistically by inspection of published laboratory data from the literature.

\subsubsection{Completion of work for Objective 1}

This Objective about finalizing the model validation has been done for both prioritized cases (CLASIC and TWP-ICE). First, project personnel worked with scientists involved in the campaigns to create realistic vertical profiles of size distributions of each aerosol species (sulphate, dust, black carbon, seasalt, 
soluble and biological/non-biological insoluble organics) to initialize the model. Figures 1-2 shows validation of cloud-particle number concentration, precipitation, and cloud fraction for CLASIC. During Year 2, the treatment of sulphate aerosol was improved. Because sulphate controls homogeneous freezing aloft, this model refinement resulted in better accuracy of ice-particle number concentrations aloft. The difference between predicted and observed ice concentrations is less than the sampling error of observations. Moreover the predicted radiative fluxes at the top of the atmosphere and surface differ by less than about $10-20 \%$ from observations in both the short- and long-wave.

Additionally, an optional case from the Arctic was simulated for the purpose of extra model validation at a different resolution. High-resolution simulations of Arctic stratocumulus cloud for 1 day of the ISDAC case were performed (Fig. 3). These runs were not part of the core work of the project, but provided extra evidence of the robustness of the model accuracy (see original proposal). Size distributions of aerosol species were initialized following Ovchinnikov et al. (2011) and Fan et al. (2011). Domainaveraged profiles of supercooled LWC $\left(\sim 10^{-4} \mathrm{~g} \mathrm{~m}^{-3}\right)$ and IWC $\left(\sim 10^{-3}\right.$ to $\left.5 \times 10^{-3} \mathrm{~g} \mathrm{~m}^{-3}\right)$ (Fig. 3) have orders of magnitude consistent with aircraft observations of multi-layered mixed-phase clouds (Fan et al. 2011, Figure 2 therein), in view of natural variability. Cloud-base and cloud-top are at realistic altitudes. Predicted concentrations of cloud-droplets and ice particles are $10-100 \mathrm{~cm}^{-3}$ and $0.1-1 \mathrm{~L}^{-1}$ respectively, similar orders of magnitude compared to ISDAC aircraft observations (e.g. Fan et al. 2011). In-cloud overturning is partly maintained by cloud-top radiative cooling, which destabilizes the layers.

\subsubsection{Completion of work for Objective 2}

The Objective 2 about impacts from soluble aerosol material on cold clouds has been completed. Figure 4 shows indirect effects from aerosol pollution on clouds and climate, predicted by the aerosol-cloud model for one of the prioritized cases (CLASIC). Aerosol pollution alters clouds and causes a cooling locally by reducing the net radiative flux entering the top of the atmosphere. The total flux change of almost $10 \mathrm{Wm}^{-2}$ is large (compares with $4 \mathrm{~W} \mathrm{~m}^{-2}$ of radiative forcing from a doubling of global $\mathrm{CO} 2$ concentrations) because of vigorous deep convection in the region simulated. Over Oklahoma in summer, convection was deep and the convective cells produced nimbostratus and cirriform clouds. In the sensitivity tests, glaciated clouds cause about $70 \%$ of the overall contribution to the radiative flux change at the top of the atmosphere (TOA) due to aerosol pollution. An altered water cycle is the chief reason, with aerosol pollution causing glaciated clouds to have a longer lifetime and be more extensive (the 'lifetime' indirect effect). Glaciated clouds' lifetime effect accounts for about two thirds of their contribution to the indirect effect, while their albedo effect creates the remaining third. More glaciated cloud reflects more sunlight to space, causing a cooling, just as warm clouds do.

Ice-only clouds were found to make the greatest contribution to this lifetime indirect effect of glaciated clouds, though mixed-phase clouds are also significant (Fig. 4). Increased number concentrations of cloud-droplets and cloud-ice are caused by the aerosol pollution, altering production of precipitation 


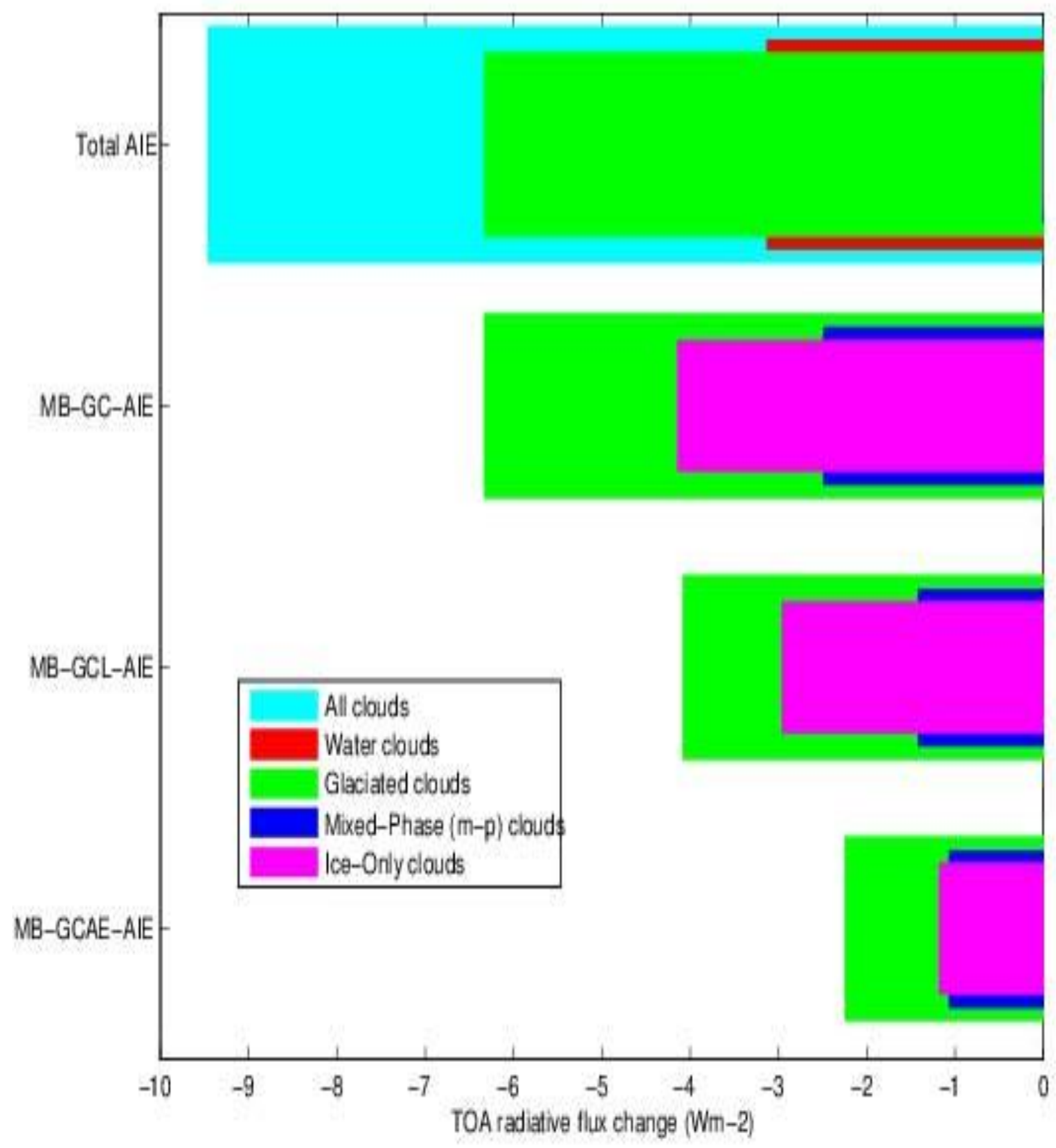

Figure 4: Indirect effects from soluble aerosols ('AIE') in pollution on the atmosphere via modification of clouds, predicted by the aerosol-cloud model in terms of the radiative flux change at the top of the atmosphere $\left(\mathrm{W} \mathrm{m}^{-2}\right)$. Shown is the total AIE (uppermost bars) for all clouds (light blue), and the component of it due to glaciated clouds (green), and liquid-only clouds (red). Relative contributions to this glaciated-cloud component of AIE (green) from mixed-phase (dark blue) and ice-only (pink) clouds are shown (bars second from top). The lifetime (bars third from top) and albedo/emissivity (lowermost bars) components of this AIE component from glaciate clouds (green) are shown. Again, contributions to them from ice-only (pink) and mixed-phase (dark blue) clouds are shown. The model simulated cloud systems over a mesoscale domain (about $200 \mathrm{~km}$ wide) from Oklahoma during summer 2007 (CLASIC), during a month of deep convection. 


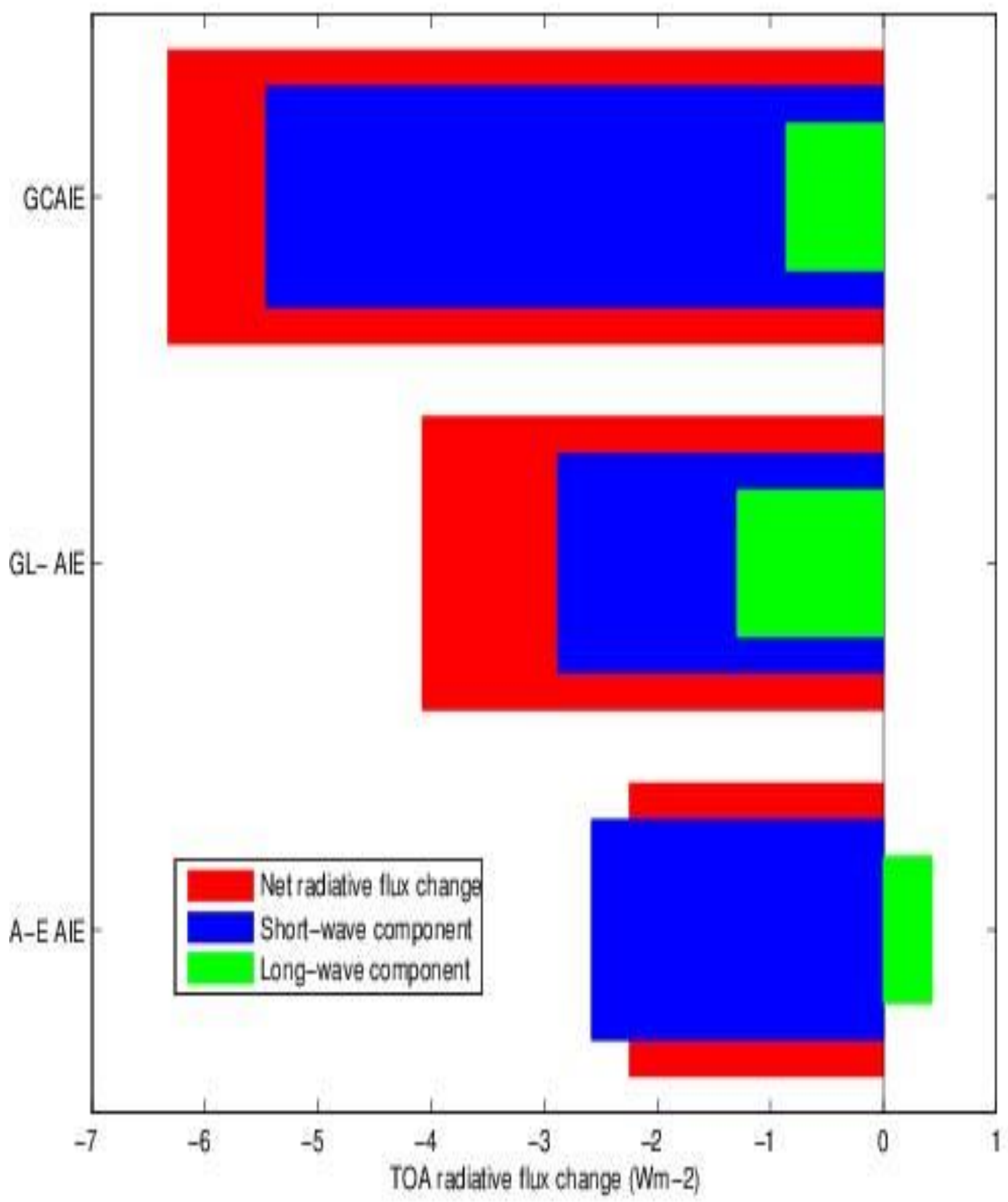

Figure 5: Analysis of short-wave (blue) and long-wave (green) contributions to AIEs ( $\mathrm{W} \mathrm{m}^{-2}$ ) of glaciated clouds (uppermost bars) and to their lifetime (middle bars) and albedo/emissivity components (lowermost bars), predicted for CLASIC. This is for the same indirect effects shown in Fig. 4. 


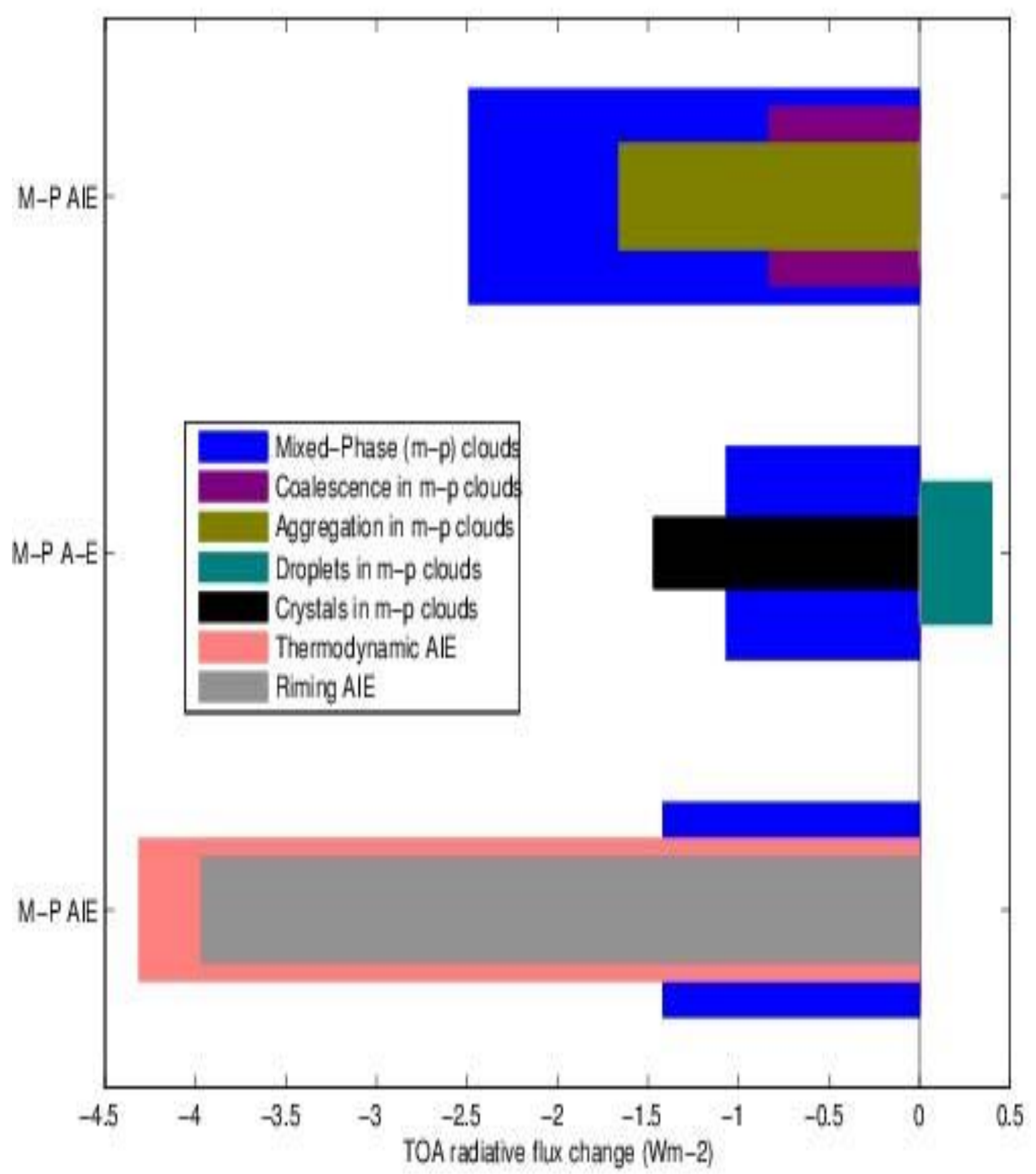

Figure 6: Microphysical analysis of AIEs $\left(\mathrm{W} \mathrm{m}^{-2}\right)$ for mixed-phase clouds in the CLASIC simulation plotted in Fig. 4. Plotted are the AIE for mixed-phase clouds (upper bars), and the components of this AIE due to albedo/emissivity indirect effects (middle bars) and lifetime effects (lower bars). The contributions to these AIEs from coalescence of extra cloud-droplets (mauve), initiated by soluble aerosol pollution, and from aggregation of ice particles (olive) from these aerosols, are shown. The riming (grey) and thermodynamic (pink) indirect effects are shown as contributions to the overall lifetime effect of mixed-phase clouds. 
and its accretion of condensate. Production of more homogeneously nucleated ice aloft, consisting of extremely numerous ice crystals, boosted the extent of cirriform (ice-only) cloud aloft. By contrast, concerning the weaker albedo/emissivity indirect effect of glaciated clouds, the balance is more even between contributions from ice-only clouds and from mixed-phase clouds.

Figure 5 shows shortwave radiation changes are the major reason for these indirect effects of glaciated clouds. There is a weak contribution to the glaciated clouds' lifetime effect from enhanced longwave emission to space. Figure 6 shows that coalescence and ice-ice aggregation, of extra cloud-particles from aerosol pollution, both contribute to the lifetime effect of mixed-phase clouds. Ice-ice aggregation in mixed-phase clouds is inhibited when pollution is present, because the higher concentrations of ice reduce the amount of moisture available for growth (e.g. less supercooled liquid for riming when there is more evaporation). This makes the mixed-phase clouds more extensive by reducing amounts of snow aloft.

Finally, Figure 6 shows that the riming and thermodynamic indirect effects make similarly large contributions to the mixed-phase clouds' indirect effect. Both cause a strong cooling. The riming indirect effect involves more numerous smaller droplets being less likely to rime onto ice precipitation. The thermodynamic indirect effect involves more intense ascent from latent heat release in freezing.

\subsubsection{Completion of work for Objective 3}

Impacts from solid aerosol material, which nucleates ice (IN aerosols), on glaciated clouds were found by sensitivity tests for this objective in the present project. The balance between ice-only clouds and mixed-phase clouds was altered, with a greater extent of ice-only cloud occurring. This changed the cloud cover and reflection of sunlight to space. Results are to be described in detail in the PhD thesis of the student performing the work at Leeds, which will soon be submitted for examination.

\subsection{Products}

These publications in a peer-reviewed journal have arisen from work funded by the award:

- Morris, C. E., Conen, F., Huffman, A., Phillips, V. T. J., Poschl, U., and D. C. Sands, 2013: Bioprecipitation: feedbacks linking Earth history, ecosystem dynamics and land use. Global Change Biology, in press

- Phillips, V. T. J., DeMott, P. J., Andronache, C., Pratt, K. A., Prather, K. A., Subramanian, R., and C. Twohy, 2013: Improvements to an empirical parameterization of heterogeneous ice nucleation and its comparison with observations. J. Atmos. Sci., 70, 378-409

- Yano, J.-Y., and V. T. J. Phillips, 2011: Ice-ice collisions: a key ice multiplication process in atmospheric clouds. J. Atmos. Sci., 68, 322-333 
- Khain, A. P., V. Phillips, N. Benmoshe, A. Pokrovsky, 2012: The role of small soluble aerosols in the microphysics of deep maritime clouds. J. Atmos. Sci., 69, 2787-2807

Support by DoE (ASR), via the PI's award, is acknowledged in these papers. Codes for the EP (Phillips et al. 2013) were shared with US Government laboratories (NASA: Barahona; PNNL: J. Fan) for assessments of how aerosol pollution affects cold clouds and hence, global warming. The EP has been shared with the German Weather Service (Seifert). Their simulations with it have informed the recent improvements to the EP, published in 2013.

\section{Conclusions}

During the project, the following conclusions were obtained:-

(1) Extra liquid aerosols (soluble aerosol material) from pollution initiated extra cloud-droplets and inhibited coalescence of supercooled cloud-droplets for precipitation production in glaciated clouds. This promoted homogeneous freezing of cloud droplets and aerosols. Mass and number concentrations of ice were boosted in glaciated clouds.

(2) Mean sizes of cloud-ice particles were reduced by the pollution, due to increased competition for vapour during diffusional growth, and so cloud fraction of mixed-phase clouds and ice-only clouds was boosted. This increased longevity of glaciated clouds was due to inhibition of sedimentation and ice-ice aggregation of smaller ice crystals.

(3) Latent heat released from extra homogeneous freezing invigorated the deepest convective updrafts reaching the upper troposphere, raising their maximum cloud-tops, in the presentday aerosol conditions (polluted) relative to pre-industrial (more nearly pristine) conditions.

(4) The radiative flux change at the top of the atmosphere (the 'aerosol indirect effect') of glaciated clouds was greater by $100 \%$, compared to that of (warm) water clouds. This is because glaciated clouds are higher in the troposphere than water clouds and have the first interaction with incoming (downward) solar radiation after it enters the atmosphere. Thus, in a column with glaciated clouds above water clouds, the glaciated clouds more readily control the reflection of sunlight to space.

(5) The increased lifetime of glaciated clouds, especially ice-only ones, due to inhibited processes of ice-ice aggregation and sedimentation provided the dominant mechanism for the glaciated clouds' indirect effect.

(6) Predicted properties of glaciated clouds were more sensitive to aerosol changes than water clouds.

(7) In addition to the known indirect effects (glaciation, riming and thermodynamic), new indirect effects were discovered and quantified due to responses of sedimentation, aggregation and coalescence in glaciated clouds to the changing aerosol conditions from pollution.

(8) The change in horizontal extent of the glaciated clouds ('cloud-lifetime indirect effects') was seen to be of higher importance in regulating aerosol indirect effects than changes in cloud properties ('cloud-albedo indirect effects').

The ice-crystal process of precipitation production is found to have paramount importance in the response of mesoscale systems of glaciated clouds to changing aerosol conditions over Oklahoma and 
the west Pacific. The ice-crystal process is naturally favoured in widespread regions of weak ascent in layer-clouds. It involves, first, initiation of ice and then vapour growth of ice crystals followed by their aggregation. Yet the last stage of this linkage is difficult to treat in atmospheric models, since the laboratory data are scarce on how to treat the sticking and collision efficiencies in ice-ice collisions. In particular, turbulent enhancement of collision efficiencies for ice-ice aggregation and for riming are uncertain. Hence, there is a need for the community to perform laboratory experiments to observe more carefully such aspects of the ice-crystal process, so that its role in mediating the aerosol/coldcloud interactions may be assessed more reliably in future. Future development of the aerosol-cloud model will focus on improvements to treating ice morphology.

\section{References}

Fan, J., Ghan, S., Ovchinnikov, M., Liu, X., Rasch, P. J., and A. Korolev, 2011: Representation of Arctic mixed-phase clouds and the Wegener-Bergeron-Findeisen process in climate models: Perspectives from a cloud-resolving study. J. Geophys. Res., 116, D00T07, doi:10.1029/2010JD015375.

Khain, A. P., Phillips, V., Benmoshe, N., and A. Pokrovsky, 2012: The role of small soluble aerosols in the microphysics of deep maritime clouds. J. Atmos. Sci., 69, 2787-2807

Lohmann, U. and J. Feichter, 2005: Global indirect aerosol effects: a review. Atmospheric Chemistry and Physics, 5 (3), 715-737, doi:10.5194/acp-5-715-2005

Morris, C. E., Conen, F., Huffman, A., Phillips, V. T. J., Poschl, U., and D. C. Sands, 2013: Bioprecipitation: feedbacks linking Earth history, ecosystem dynamics and land use. Global Change Biology, in press

Ovchinnikov, M., Korolev, A., and J. Fan, 2011: Effects of ice number concentration on dynamics of a shallow mixed-phase stratiform cloud. J. Geophys. Res., 116, D00T06, doi:10.1029/2011JD015888

Phillips, V. T. J., and co-authors, 2005: Anvil glaciation in a deep cumulus updraft over Florida simulated with an Explicit Microphysics Model. I: The impact of various nucleation processes. Q. J. R. Meteorol. Soc., 131, 2019-2046

Phillips, V. T. J., DeMott, P. J., and C. Andronache, 2008: An empirical parameterization of heterogeneous ice nucleation for multiple chemical species of aerosol. J. Atmos. Sci., 65, 2757-2783

Phillips, V. T. J., and co-authors, 2009: Potential impacts from biological aerosols on ensembles of continental clouds simulated numerically. Biogeosciences, 6, 1-28

Phillips, V. T. J., Demott, P. J., Andronache, C., Pratt, K. A., and C. Twohy, 2013: Improvements to an empirical parameterization of heterogeneous ice nucleation and its comparison with observations. $J$. Atmos. Sci., 70, 378-409. 
Solomon, S., D. Qin, M. Manning, Z. Chen, M. Marquis, K. Averyt, M.Tignor, and H. M. (eds.), 2007: Climate change 2007: The physical science basis. Contribution of working group $i$ to the fourth assessment report of the intergovernmental panel on climate change, (ipcc). Cambridge University Press, Cambridge, United Kingdom and New York, NY, USA., 4th.

Streets, D. G., and co-authors, 2003: An inventory of gaseous and primary aerosol emissions in Asia in the year 2000. J. Geophys. Res, 108 (8809), D21, doi:doi:10.1029/2002JD003093. 